\title{
La contratación por medios electrónicos en el marco de la Comunidad Andina. Estado del arte*
}

\author{
The electronic procurement in the framework of the Andean \\ Community. State of the art \\ Recibido: 12 de febrero de 2009 - Revisado: 23 de marzo de 2009 - Aceptado: 03 de julio de 2009
}

William David Hernández Martínez ${ }^{* *}$

\section{Resumen}

El artículo se estructura como un breve estudio de los planteamientos académicos y políticos acerca de la unificación o armonización de la normatividad respecto del comercio electrónico, específicamente lo referente a la contratación por medios electrónicos en América Latina, con especial énfasis en la Comunidad Andina, como una labor propuesta en desarrollo de las tendencias modernas del Derecho Mercantil Internacional.

Palabras claves

Armonización, unificación, Comunidad Andina, comercio electrónico, contratación electrónica.

\footnotetext{
Abstract

The article is structured as a brief survey of the academic and policy approach on the unification or harmonization of regulations about electronic commerce, specifically relating the electronic contracts, in Latin America, with special emphasis on the Andean Community of Nations as a proposed work on the development of modern trends of international trade law.

Key words

Harmonization, Unification, Andean Community, Electronic Commerce, Electronic Contracts.
}

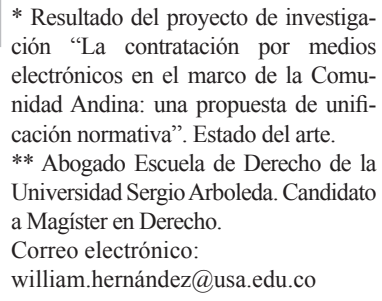

* Resultado del proyecto de investigación "La contratación por medios electrónicos en el marco de la Comunidad Andina: una propuesta de unificación normativa". Estado del arte.

** Abogado Escuela de Derecho de la Universidad Sergio Arboleda. Candidato a Magíster en Derecho.

Correo electrónico:

william.hernández@usa.edu.co 


\section{Introducción}

El mundo actual, enmarcado en un proceso de globalización e integración regional, se encamina hacia a la armonización normativa como elemento generador de una ventaja cooperativa, conceptos igualmente válidos para el comercio electrónico que, sin lugar a dudas, es una expresión de la moderna lex mercatoria.

En consonancia con lo anterior, esta investigación pretende estudiar la regulación actual en cada uno de los países miembros de la Comunidad Andina (organismo de integración regional al cual pertenece Colombia) respecto de la contratación por medios electrónicos, con el fin de determinar los elementos legales que posibiliten la unificación normativa en esta materia.

De acuerdo con lo anterior, el presente artículo busca realizar un estudio del estado del arte, esto es la revisión de los diferentes planteamientos, académicos y políticos que sobre el objeto de estudio propuesto se han realizado. Para ello, el escrito se encuentra divido en cuatro acápites a saber: 1. El planteamiento del problema de investigación; 2. La descripción de la metodología a emplear; 3. La revisión del estado del arte desde dos perspectivas, estas son: i) la perspectiva regional e internacional y ii) la visión nacional, y 4. Algunas conclusiones sobre el particular.

\section{Problema de Investigación}

No es novedoso afirmar que las Tecnologías de la Información y las Comunicaciones (TIC) han incidido en todos los aspectos de las sociedades (económicas, sociales, políticas, entre otros), sin embargo, este hecho incuestionable implica, para el derecho, la responsabilidad ineludible de propiciar el cumplimiento de las declaraciones o finalidades de la Cumbre Mundial de la Sociedad de la Información (Cumbre Mundial sobre la Sociedad de la Información, 2004).

En este sentido, y dada su función reguladora de las relaciones sociales encaminada al mantenimiento de la convivencia al interior de la sociedad, el derecho es un elemento fundamental en el desarrollo de la denominada Sociedad de la Información (Reusser, 2003), ya que así como no se concibe una vida social sin derecho, no es aceptable el desarrollo de las nuevas tecnologías sin regulación.

Ahora bien, al abordar el recorrido histórico de las instituciones legales, es evidente que estas, las instituciones, encuentran su origen en los usos y prácticas de los comerciantes, hoy considerados desde la perspectiva del concepto de empresa (Galgano, 2005, pág. 35; García, 2006), el legislador, entonces, se concentra en dotar de estabilidad, certeza y generalidad las bases dictadas por la praxis social (Corte Constitucional, 1993, Sentencia C-486, pág. 8, consid. 5).

El comercio electrónico, entendido como las transacciones comerciales realizadas o basadas en sistemas electrónicos de procedimiento $\mathrm{y}$ transmisión de información (Remolina, 2006, pág. 2), derivadas de la aplicación de las Tecnologías de la Información y las Comunicaciones (TIC) a la gestión empresarial contemporánea (Rincón, 2004; 2006b, págs. 19 a $23)^{1}$, no es ajeno a esta realidad, esto ha suscitado al interior de los Estados la necesidad de establecer un marco normativo amplio (Olivera y Proto, 2006), manteniendo la tendencia de la lex mercatoria moderna, entendida como un orden jurídico que insta a la autorregulación, esto es, la posibilidad de los agentes del comercio internacional de reemplazar la ley por el contrato, el juez por el arbitraje (Galgano, 2005, pág. 105)2, y por tanto se caracteriza por su "anacionalidad" (Fernández, 2007, págs. 57 a 58; 2004, págs. 95 a $96 ; 2000)$.

Bajo el anterior supuesto, esto es, el comercio electrónico como una expresión de la moderna lex mercatoria, las reglas de derecho aplicable a las diferentes relaciones o vínculos jurídicos surgen de los mismos comerciantes quienes, a través de sus usos y prácticas, ya han comenzado a crear costumbres. 
Como evidencia de lo anterior, se rescata el trabajo del grupo de trabajo de prácticas en el comercio electrónico de la Cámara de Comercio Internacional al presentar el borrador de las Reglas Uniformes y Guías para el Comercio y Pago Electrónico (URGETS) ${ }^{3}$, mediante las cuales se recogen las costumbres en aras a uniformizar los contratos electrónicos (Calderón, 2000; Cibertribunal Peruano, 2008).

Ahora bien, la formulación de políticas y normas respecto del e-business ${ }^{4}$ acusa una gran variedad de problemas, entre los cuales se pueden señalar la indeterminación geográfica de las partes, la desconfianza del usuario en las transacciones, la falta de protección del consumidor, entre otros (Ahon, 2006). En torno a estos interrogantes, se destaca la necesidad de poseer estándares básicos que doten de plena validez a los actos, contratos y negocios que surgen en torno de las TIC a nivel mundial y, en consecuencia, a proyectar sobre los actores la seguridad jurídica ${ }^{5}$ necesaria en este tipo de transacciones, a veces denominada lex retialis ${ }^{6}$ (Olivera, 2008, pág. 8).

El primero de los antecedentes en este sentido es la denominada "Ley Modelo de Comercio Electrónico" (en adelante LMCE) formulada por la Comisión de las Naciones Unidas para el Derecho Mercantil Internacional (CNUDMI o UNCITRAL, por su sigla en inglés) $)^{7}$, y que tiene por objeto ofrecer un conjunto de reglas internacionalmente aceptables que puedan ser empleadas por los Estados para superar los obstáculos e incertidumbres jurídicas que existan en relación con el uso de los medios de comunicación electrónicos en el comercio internacional.

Sin embargo, su carácter meramente sugestivo concluye en la imposibilidad de generalizar sus disposiciones. Este es el caso de los países latinoamericanos, en los cuales encontramos una variedad de orientaciones (UNCITRAL, $\mathrm{Utah}^{8}$ y normatividad europea) en las legislaciones existentes, sin contar con el caso de Bolivia en el cual no se ha formulado una normatividad sobre el tema9 .

De conformidad con las consideraciones anteriores, se evidencia la necesidad de crear dentro de las organizaciones regionales existentes, en el caso latinoamericano la Comunidad Andina (CAN), la posibilidad de regular o "normatizar" de forma clara $\mathrm{y}$, sobretodo, uniforme, diversos aspectos del comercio electrónico (Silveira, 2001).

De esta necesidad de armonización y unificación surge el objeto propio de esta investigación, sintetizado metodológicamente en la siguiente pregunta jurídica: ¿es posible alcanzar la unificación normativa al interior de la Comunidad Andina respecto de la contratación por medios electrónicos?

El problema que inspira esta investigación es dotar de seguridad y privacidad los actos, negocios y transacciones que se realizan a través de medios electrónicos. Remolina (2006) expone como los principales factores de desconfianza en los negocios electrónicos, los siguientes: $i)$ el anonimato de las transacciones; ii) la dificultad de garantizar la confidencialidad; iii) integridad y repudio de los "documentos" y iv) la barrera cultural delimitada en el bajo acceso a las TIC.

\section{Metodología}

La investigación planteada es una investigación básica jurídica que tiene por objeto el estudio de las normas que sobre la contratación electrónica se han promulgado en los países miembros de la CAN (Bolivia, Colombia, Ecuador y Perú), así como la jurisprudencia y doctrina que sobre el particular se profiera, en aras de contribuir en la formulación de principios y reglas de validez con aplicación general, inspirados en la experiencia de la Unión Europea, que se integren al Derecho Uniforme del Comercio Internacional (DUCI) ${ }^{13}$, de tal forma que los 
hallazgos sirvan como sustento de proyectos de unificación y armonización (Fernández, 2007, págs. 59 a 62; 2004, págs. 97 a 100; 2000).

El camino o procedimiento a seguir en esta investigación, esto es la lógica metodológica a modo de ayuda o mecanismo para la facilitación de los procesos mentales de investigación, cuenta con las siguientes características (Bulla Quintana, 2008, pág. 247):

- En cuando al modo por el cual se procede, se utilizará un método sintético ideal, en el cual se estudiarán los efectos de los medios electrónicos en cada uno de los países de la Comunidad Andina, con el fin de formular una visión unitaria o general de principios aplicables en forma universal a los miembros.

- En la demostración se utilizará un procedimiento inductivo, en tanto el punto de partida son situaciones singulares, es decir, la normatividad particular de los países, con aspiraciones de formulación de proposiciones generales ${ }^{14}$.

- Así mismo, y dadas las características propias del objeto de investigación, se propende por una investigación racional ${ }^{15}$, fundamentos de autoridad $^{16}$, con una finalidad heurística ${ }^{17}$.

El proceso de búsqueda, selección e inventario de las fuentes del conocimiento ${ }^{18}$, o de la información, se concentrará, respecto de fuentes primarias y secundarias, en el tratamiento dentro de los países miembros de la Comunidad Andina de la contratación por medios electrónicos. Las fuentes de conocimiento deben examinarse, interna y externamente ${ }^{19}$ mediante un énfasis comparativo de las condiciones similares de las fuentes, para que bajo el amparo de la metodología planteada con anterioridad se logre la enunciación y explicación de principios de carácter general y aplicación universal.

Comoelementointegrantedeconocimiento, ya sea como aplicación curricular o investigativa, se resalta la necesidad de interdisciplinariedad ${ }^{20}$. La presente investigación se presenta como acorde al núcleo común o «common core» que se extracta de la justificación y objetivos de algunos programas de la Universidad Sergio Arboleda y que se puede denominar "Desarrollo Económico y Empresarial"21, encaminado al desarrollo de conocimientos relacionados con el emprendimiento, dirección y negociación empresarial en el cual se fortalezca la relación Universidad - Empresa - Estado - Sistema Económico Mundial, enmarcados en un mundo globalizado, y que se caracteriza por los procesos de integración regional y mundial en búsqueda de ventajas cooperativas ${ }^{22}$, y propenso a la armonización y unificación de los diferentes sistemas.

Así mismo, el núcleo temático mencionado integra armónicamente: $i$ ) las ciencias humanísticas (filosofía, historia, derecho, pedagogía, entre otras); ii) las ciencias económicas (economía, finanzas, contabilidad, estadística, etc.); iii) las ciencias exactas (matemáticas, cálculo), y iv) la ciencia política (relaciones internacionales, modelos de integración, las organizaciones internacionales).

La investigación propuesta se orienta en la búsqueda de aspectos comunes de la institución contractual respecto de un elemento específico que es el uso de las TIC, partiendo de la base del proceso de regionalización e integración, llevado a cabo en la Comunidad Andina, sin olvidar que en la actualidad se reconoce la existencia de un nuevo ciudadano, el «ciudadano económico» ${ }^{23}$, que se resiste a ser considerado como objeto jurídico y demanda un papel o rol en la economía global, fomentando la "autorregulación". 


\section{Estado del arte}

Para sintetizar lo hallado respecto de la contratación por medios electrónicos desde la perspectiva de la unificación normativa, es preciso abordar su estudio en forma fraccionada: i) en primer lugar, analizar los escritos e investigaciones que en el enfoque regional e internacional se han presentado; ii) seguidamente, se examinarán algunos referentes nacionales relacionados con el objeto de estudio propuesto.

\subsection{Desde la perspectiva regional}

A nivel regional, se destaca que desde el año 2000 las autoridades de telecomunicaciones de los entonces cinco países de la CAN suscribieron el "Documento de Lima sobre la Sociedad Global de la Información" en el cual convienen, además de constituir como objetivo común el garantizar el acceso de la población a los servicios de telecomunicaciones, establecer normas que doten de seguridad las diferentes fases de las operaciones comerciales que utilizan recursos electrónicos, entre ellas el pedido, la contratación, el pago, la entrega, la devolución, así como la verificación de firmas electrónicas y la constitución de entidades de certificación.

Sobre este particular, Cárdenas Zorro (2000) afirma que el propósito de la CAN de conformar un mercado común en el año 2005 está estrechamente vinculado a la efectiva prestación de los servicios propios de la Sociedad de la Información entre los países miembros. Así pues, dentro de las dificultades en el tema, el autor destaca que, a la fecha del documento, apenas el $2 \%$ de la población andina tiene Internet, las políticas gubernamentales no son adecuadas, la infraestructura tecnológica es inapropiada y la existencia de una "inseguridad jurídica" en el tema es palpable.

Concluye Cárdenas Zorro (2000) que la Comunidad Andina debe iniciar un proceso para ir eliminando gradualmente los obstáculos políticos, técnicos y jurídicos mencionados; ahora bien, en torno a los problema jurídicos se evidencia la necesidad de establecer un marco jurídico armónico, claro, sencillo y compatible con las normas vigentes a escala internacional, siguiendo el ejemplo de la Unión Europea.

Por lo que respecta al propósito o finalidad de los países miembros de la Comunidad Andina en lo concerniente a la contratación electrónica, proclamado en la Declaración de Lima, impactó, de manera gradual, los distintos ordenamientos jurídicos en tanto se expidieron en su cumplimiento diversas reglamentaciones en cada uno de los países miembros:

- Colombia ya contaba con la Ley 527 de $1999^{24}$, por medio de la cual se define y reglamenta el acceso y uso de los mensajes de datos, de las firmas digitales y se establecen las entidades de certificación. Posteriormente, se reglamentó lo atinente a las entidades de certificación, los certificados y las firmas digitales mediante el Decreto 1747 de $2000^{25}$.

- Ecuador expidió la Ley 67 de $2002^{26}$, reglamentada mediante el Decreto 3496 del 31 de diciembre $2002^{27}$, normas mediante las cuales se establecen los parámetros jurídicos sobre los mensajes de datos, la firma electrónica, los servicios de certificación, la contratación electrónica, la prestación de servicios elec-trónicos (incluido el comercio electrónico) y la protección a los usuarios. A primera vista, parece ser la legislación más completa sobre el tema a nivel de la Comunidad Andina, puesto que contiene un capítulo específico orientado a la protección de los derechos del consumidor o usuario de servicios electrónicos. 
- Perú ha desarrollado dos acercamientos regulatorios: en primer lugar, formuló la Ley 27269 de $2000^{28}$, mediante la cual se regula la utilización de la firma electrónica y el funcionamiento de las entidades de certificación. A su vez, incorporó algunas modificaciones al Código Civil con el fin de permitir la manifestación de la voluntad a través de medios electrónicos y por lo tanto celebrar válidamente contratos utilizando medios electrónicos (Ley 27291 de 2000) $)^{29}$.

Por otro lado, en el marco del Proyecto Andino de Competitividad, Araoz y Van Ginhoven (2001), del Centro de Investigación de la Universidad del Pacifico (Perú), evalúan la preparación de los países andinos para integrar las redes de tecnologías de la información, estudiando particularmente el caso peruano, determinan que con la legislación actual, a nivel interno, se pueden satisfacer algunas necesidades, pero en un mundo globalizado es necesario propugnar por una integración normativa.

De lo anterior, surge rápidamente una primera conclusión orientada a que la preocupación por la integración o armonización normativa a nivel de la Comunidad Andina es latente, razón por la cual es imperativo determinar los elementos legales que posibilitan la unificación normativa como un mecanismo para incrementar la competitividad de los países miembros en aras de mejorar la ventaja cooperativa de la región ante los nuevos miembros de la comunidad económica mundial.

En este sentido, Silveira (2001) escribe para la Revista de Contratación Electrónica ${ }^{30}$ un artículo titulado "Repercusiones internacionales del comercio de electrónico: el marco legal del comercio electrónico en América Latina y la necesidad de armonizar la normativa aplicable", del cual se destaca un interés especial en el establecimiento de Normas Uniformes sobre Documentos y Firmas electrónicas a nivel Americano, sobre la base de la neutralidad normativa (en oposición a la especialización que caracteriza algunas legislaciones) y una perspectiva real de la situación regional.

Así mismo, describe como elementos que impiden la adaptación de las normas a la realidad Latinoamericana los siguientes: i) la terminología empleada; ii) la elección de la ley y la jurisdicción aplicable; iii) las entidades de certificación, y iv) la protección al consumidor, como el gran reto del legislador.

Por su parte, la Asociación Latinoamericana de Integración (ALADI) ${ }^{31}$ celebró, en el mes de junio de 2001, un seminario denominado Situación Actual y Perspectivas del Comercio Electrónico en la Región, en el cual se resaltó la importancia de elaborar y proponer la generación de directrices comunes básicas para la regulación del comercio electrónico en Latinoamérica, en tanto se requiere desarrollar un sistema regulatorio claro y predictible con estabilidad en el tiempo, no discriminatorio y que otorgue el marco jurídico adecuado para la expansión del acceso a las TIC, el cual debe reposar sobre una cuestión central: el desarrollo de una normativa contractual vinculante, con un derecho y con una jurisdicción aplicable.

Este mismo organismo presentó, en el año 2007, un "estudio comparado sobre la definición y consideración de los temas vinculados a las Tecnologías de la Información y las Comunicaciones (TIC) en otros esquemas de integración regional", en el cual se identifica $\mathrm{y}$ escribe el tratamiento que adoptan otros esquemas de integración regional ${ }^{32}$ respecto de la infraestructura de TIC, comercio y gobierno electrónico, uso de documentos electrónicos y firma digital, brecha digital y la normativa correspondiente.

El mencionado estudio destaca que la CAN se ha esforzado en aumentar el acceso a 
las TIC y reducir la brecha digital, sin embargo no ha realizado reglamentaciones específicas sobre temas de gran importancia en el uso de las TIC, tales como: seguridad, firmas digitales, protección de datos, entre otros ${ }^{33}$.

Ahora bien, la Sexta Conferencia Especializada Internacional sobre Derecho Internacional Privado (CIDIP-VI) ${ }^{34}$, aprobó la Resolución N. ${ }^{\circ} 05$ del 8 de febrero de 2002, en la cual recomienda a los Estados miembros de la Organización de Estados Americanos la adopción de regímenes legales sobre documentos y firmas electrónicas compatibles con los instrumentos internacionales, especialmente con las Leyes Modelo elaboradas por CNUDMI en 1996 y 2001.

Es importante resaltar que la delegación de Estados Unidos, como documento de trabajo previo, aportó a la CIDIP-VI, un proyecto de Reglas Uniformes Interamericanas en materia de Documentos y Firmas Electrónicos, caracterizado por sus disposiciones predominantemente autorregulatorias para los actores del comercio internacional ${ }^{35}$.

Respecto al proyecto en mención, la CIDIP-VI manifestó su interés así como recomendó a los países el estudio del mismo para que en el marco de la soberanía estatal consideren su integración como legislación nacional, pero sin definir una posición clara sobre su pertinencia, contenido o aplicación.

La Misión Permanente de Estados Unidos (2004) propuso que la CIDIP-VII, para la que a la fecha del presente documento no se le ha fijado fecha de realización, abordara el estudio del proyecto, sin embargo la Asamblea General de la OEA determinó, mediante Resolución 2217 del 6 de junio de 2006, que los esfuerzos durante la séptima versión de la CIDIP se orientarían a establecer instrumentos unificados en torno a la Protección del Consumidor y a Registros de Garantías Mobiliarias. Con lo anterior, se aleja la posibilidad de encontrar el apoyo a una propuesta unificada alrededor del valor jurídico de los documentos y firma electrónicos por parte de la Organización de Estados Americanos.

La decisión de la Asamblea General de la OEA se explica si se tiene en cuenta lo expuesto por Hilbert, Bustos y Ferrat (2003) en un informe para la Comisión Económica para América Latina y el Caribe - CEPAL - , en el cual, luego de describir el incipiente estado de desarrollo de la Sociedad de la Información en América Latina y el Caribe, resaltan que las estrategias nacionales están principalmente orientadas hacia los problemas básicos de infraestructura, en comparación con Europa y Estados Unidos en donde el debate se centra en temas avanzados como la privacidad y confianza del consumidor y la legalidad de las actividades digitales.

En consonancia, no sorprende que América Latina y el Caribe centren su desarrollo normativo y de planeación en temas como el acceso y la conectividad a las TIC y sean vistas como políticas para la infraestructura tecnológica, relegando a un segundo plano las políticas orientadas a modificaciones sociales, económicas o jurídicas.

Ahora bien, Iriarte (2003) publica un informe sobre el Comercio electrónico en América Latina, en el cual destaca el esfuerzo de algunos Estados en la formulación de políticas, pero expresa que las diferencias entre ellas no favorecen el progreso regional y, por el contrario, estancan los esfuerzos de construir un bloque sólido y unificado.

El mismo autor, en un artículo titulado "Comercio Electrónico en América Latina: Realidades y Perspectivas", publicado por el Monitor de Políticas TIC en América Latina y el Caribe en el año 2006; realiza un acercamiento a la situación del comercio electrónico en la región, enumerando y describiendo algunos de los problemas en la 
armonización a nivel regional, resaltando la diversidad de inclinaciones que se presentan como un obstáculo para el desarrollo integral del comercio regional.

A su turno, Katz y Hilbert (2003) en un estudio para la Comisión Económica para América Latina y el Caribe - CEPALrecomiendan, como un elemento principal para la creación de un marco regulatorio para América Latina y el Caribe, alentar las comunicaciones y transacciones digitales mediante el agotamiento de los debates en torno a temas como la seguridad y confiabilidad, la certificación y los contratos electrónicos, los sistemas de pago electrónico y la protección al consumidor.

Así mismo, del informe se concluye que el marco normativo, esto es la legislación, sobre los ámbitos electrónicos constituyen un área política que debe considerarse al interior de los bloques comerciales, de forma armónica con las tendencias y propuestas mundiales, pues en los casos en los cuales se produzcan efectos comerciales negativos se acude a medidas regulatorias de equivalencia comercial.

Por su parte, Gorena (2004) expone que el incipiente desarrollo en la utilización del comercio electrónico al interior de la Comunidad Andina ha impedido que se dimensione la importancia y los beneficios de esta moderna herramienta. En este sentido, los legisladores han realizado esfuerzos en la búsqueda de respuestas reguladoras al conjunto de problemas del comercio electrónico. $\mathrm{La}$ situación de la CAN es "embrionaria" pues, en criterio del autor, no existen disposiciones legales que regulen esta actividad, razón por la cual la situación comunitaria es aún más precaria que la de los países. Continúa el autor explicando que la lamentable situación descrita anteriormente incide en el desaprovechamiento de las posibilidades que ofrece el comercio electrónico para el desarrollo empresarial y económico de la región.
Concluye Gorena (2004) afirmando que el desarrollo de un marco legislativo para el comercio electrónico debe iniciar en el ámbito contractual, esto es con el desarrollo previo de normas jurídicas que regulen la contratación digital y faciliten la identificación de los contratantes, permitiendo el perfeccionamiento $\mathrm{y}$ asignando efectos legales a las transacciones por medios electrónicos, en contravía del ambiente legal basado en el papel.

Pero Gorena (2004) va más allá al proponer la creación de una entidad certificadora comunitaria como mecanismo para el desarrollo de un adecuado sistema de acreditación o legalización, que permita el surgimiento de efectos de responsabilidad civil y penal de personas determinadas.

Dreyzin (2005), al analizar quién y cómo se debe reglamentar el comercio electrónico, expone que, a efectos de determinar la "ley" aplicable a las relaciones jurídicas de naturaleza privada que se generan en este contexto, se han formulado diferentes teorías.

La más primaria de ellas es la argumentación planteada por quienes entienden (por ejemplo, John Barlow) que al no tener dueño, el ciberespacio no queda sujeto a las reglas nacionales que aplican los Estados en sus respectivos territorios. Teoría ya desechada, pues parece olvidar que en estas relaciones jurídicas surgen conflictos que precisan de solución, además, porque esta enunciación torna en utópicos sus fundamentos al separar, de manera tajante, el mundo real del ciberespacio, como si no estuvieran protagonizados ambos por equivalentes actores.

Por otra parte la autorregulación, planteamiento defendido por quienes optan por pensar que la "red" debería estar gobernada por los propios interesados, esto es por los usuarios, justificando su posición en la analogía entre la lex mercatoria y la lex informática. La autorregulación posee una gran acogida en 
las relaciones comerciales $\mathrm{B}_{2} \mathrm{~B}^{36}$, pero en el actual contexto del comercio electrónico surge la siguiente pregunta: ¿cómo alcanzar consenso entre los millones de usuarios que hoy operan valiéndose de la vía electrónica? Concluye la autora que el pretendido carácter consensual de las normas elaboradas por los interesados encuentra una barrera en la dificultad de lograrse en forma generalizada en un marco tan heterogéneo, más aún si se tiene en cuenta que la desconfianza y la falta de seguridad y protección al consumidor son dificultades generalizadas en el ámbito del e-commerce.

En oposición a lo anterior, surge el Estado como ente regulador, en otras palabras, como sujeto idóneo para asumir la creación de normas jurídicas en función de la legitimidad democrática que los caracteriza tanto para elaborar las reglas como para hacerlas cumplir, bajo la premisa que el ciberespacio no es un lugar nuevo sino, en todo caso, un lente o un filtro a través del cual se mira el mundo.

Concluye Dreyzin (2005), afirmando que cuando los Estados, individualmente considerados, reglamentan el comercio electrónico, tienden a establecer un sistema de normas que atienda una necesidad particular e individual bajo un esquema de espacio-tiempo limitado, dejando de lado la internacionalidad como elemento sustancialmente inherente al fenómeno. Dicho carácter conduce a reflexionar acerca del tratamiento jurídico más conveniente para su regulación.

En este sentido, aunque es importante contar con fuentes nacionales, la metodología apropiada para eliminar la disparidad de los ordenamientos "domésticos" es la unificación normativa, en el entendido que este nuevo marco jurídico reconocerá la vocación internacional y lo cambiante de las situaciones particulares propias del comercio electrónico.

Finalmente, se destaca el trabajo desarrollado por la Cámara de Comercio Internacional
$(2004)^{37}$ en la divulgación y fomento de los e-terms ${ }^{38}$ como elemento convencional encaminado a "atacar" el vacío normativo que en algunos países controvierte la validez de los actos y contratos realizados o comunicados por medios electrónicos.

Para concluir con este acápite, se resalta que existen documentos, académicos y políticos, que muestran la necesidad de armonizar o unificar la normativa respecto del entorno digital. Sin embargo, el atraso en infraestructura, equipos, acceso y tecnologías orientan las políticas nacionales hacia temas básicos, alejándose del debate sustancial que se viene dando en Europa y Estados Unidos.

\subsection{Desde la perspectiva nacional}

Los estudios realizados en el ámbito nacional son, predominantemente, ajustados a las instituciones, principios o normas propias de cada legislación. En este sentido, es preciso destacar algunos planteamientos que puedan proyectar elementos a la investigación, teniendo en cuenta que ésta se orienta hacia el establecimiento de un régimen unificado de contratos electrónicos.

\section{- Bolivia}

Los estudios respecto al impacto que recibe el ordenamiento jurídico Boliviano, y en particular la institución contractual por la irrupción de los medio electrónicos, son escasos.

Laguna (2005), en un artículo para la Revista Informática Alfa Redi, expone que la celebración de contratos virtuales o electrónicos no es una figura exclusiva del Derecho de Comercio, pues la celebración de "Contratos del Derecho Civil" también se realizan por los medios virtuales, como es el caso de la adquisición de bienes o de servicios para uso doméstico o personal. Continúa Laguna expresando que si bien el uso de la 
telecomunicación no transforma el Derecho Civil, el adecuar la doctrina a este tipo de relación contractual implica, como elemento necesario, el "bosquejar" nuevos conceptos relativos al contrato virtual desde la perspectiva del Derecho Civil.

Para este efecto, el autor se centra en los principios de la LMCE tales como, equivalencia funcional y neutralidad tecnológica. Concluye Laguna destacando la necesidad de establecer un marco jurídico propio para Bolivia, con el cual se irradien de eficacia, eficiencia, oportunidad y economía las relaciones contractuales.

Por otra parte, Jijena (2006) estudia el contenido y alcance de un proyecto de Ley de Comunicación electrónica de datos, firmas electrónicas y comercio electrónico para Bolivia, con base en los trabajos preliminares del mismo, resumiendo sus objetivos de la siguiente forma: i) regular los documentos y/o mensajes soportados electrónicamente, tanto públicos como privados, que dejen constancia del otorgamiento o la celebración de actos o contratos de cualquier naturaleza; ii) el uso en ellos de mecanismos de firma electrónica; iii) el valor legal y probatorio de los documentos firmados electrónicamente; iv) los requisitos para su almacenamiento en repositorios, y $v$ ) los requisitos, obligaciones y responsabilidades de las entidades certificadoras privadas (empresas) o públicas (servicios) que autentiquen la identidad electrónica de los signatarios y, previa y obligatoriamente acreditadas ante una entidad fiscalizadora o por la ley - como ocurre con los servicios públicos-, presten servicios de certificación electrónica.

\section{- Colombia}

En el entorno colombiano se destaca el trabajo realizado por Rincón Cárdenas, que podemos ilustrar de la siguiente manera:

- En el artículo encabezado "Últimos retos para el derecho privado: las nuevas tecnologías de la información" (2004), aborda algunos de los principios de la contratación electrónica en Colombia así como el estudio de la influencia de las TIC en algunos sectores, como el bancario. Igualmente, estudia las repercusiones en torno de la propiedad intelectual en el uso de medios electrónicos. Respecto del tema objeto de estudio en la investigación propuesta, propone "actualizar" los conceptos tradicionales que describen la validez de los contratos (entre ellos, la capacidad de los contratantes y la causa de los contratos) para "sintonizarlos" con las novedades que traen consigo las TIC. En particular, aboga por la concreción de normas comunitarias $\mathrm{o}$ internacionales aplicables a la contratación electrónica, que se adecúen a las reglas de la Organización Mundial del Comercio y, a su vez, a normas de propiedad intelectual y respeto a la privacidad y seguridad de las operaciones.

- El libro titulado Manual de derecho de comercio electrónico y de Internet (2006a) realiza un acercamiento a los conceptos y principios básicos de los negocios jurídicos realizados mediante canales o medios electrónicos. Aunque el texto no pretende sentar bases teóricas, constituye un referente de la concepción actual de la contratación electrónica en Colombia.

- Finalmente, Rincón dirigió la edición de un libro de varios autores denominado Contratación Electrónica (2006b), del cual se destacan los siguientes referentes:

a. Umaña (2006), en un capítulo denominado "Contratación elec- 
trónica internacional", sostiene, luego de estudiar algunos instrumentos internacionales como la Convención de Naciones Unidas sobre la Compraventa Internacional de Mercaderías, a la luz de la contratación electrónica, que los mecanismos tradicionales de regulación no son apropiados para la contratación por medios electrónicos. Por el contrario, se ha creado una lex electrónica como una "normativa" supranacional, compuesta por un conjunto de principios, que no poseen un origen estatal, cuya aplicación depende de la autonomía de las partes o de las prácticas internacionales ${ }^{39}$. A este cuerpo normativo se integrarían, también, los usos y prácticas del comercio electrónico internacional. Así como las decisiones jurisprudenciales que sobre el mismo se profieran.

Concluye Umaña, resaltando que la autonomía de la voluntad privada es el mecanismo de regulación, que cuenta con los mejores elementos para enfrentarse a los retos que trae consigo la contratación por medios electrónicos.

b. Rodríguez (2006) estudia diversos aspectos de la contratación electrónica en el ámbito bancario, principalmente en el estudio de los contratos que se pueden celebrar por medios electrónicos, algunos de los cuales también se pueden ejecutar por dichos medios.

Así mismo, recoge en tres grupos los riesgos derealizar operaciones bancarias o comerciales por medios electrónicos, a saber: i) los riesgos operacionales, entendiéndose como los riesgos de seguridad interna y externa, el empleo inadecuado del sistema o la comisión de errores en el mismo; ii) los riesgos de reputación, referentes a la imagen o proyección de la entidad pues, al penetrar en el medio electrónico, encontrarán clientes más exigentes, para lo cual la entidad debe contar con un alto grado de conocimiento y confiabilidad, y iii) el riesgo legal, generado en el vacío o las lagunas de la actual regulación, dentro de las cuales resalta la compleja definición de la ubicación geográfica de las operaciones.

Ahora bien, Remolina (2006), investigador y director del Grupo de Estudios en Internet, Comercio electrónico, Telecomunicaciones e Informática (GECTI) de la Universidad de los Andes, al estudiar los aspectos legales del comercio electrónico, la contratación y la empresa electrónica, concluye que el uso de las tecnologías no significa que los fundamentos tradicionales de la contratación hayan desaparecido sino que, por el contrario, los principios jurídicos que rigen la formación de los actos y contratos continúan teniendo aplicación en el contexto de la contratación a través de las TIC.

En ese sentido, los elementos esenciales del negocio jurídico no deben modificarse cuando el contrato se perfecciona por vía electrónica, ya que se trata sólo de un nuevo medio de representación de la voluntad negocial ${ }^{40}$.

Como elemento característico del escrito, se destaca que Remolina (2006) incluye dentro 
de los preceptos esenciales de la contratación electrónica algunos de los principios incorporados por el Instituto Internacional para la Unificación del Derecho Privado -UNIDROIT- $(2004)^{41}$, algunos de los cuales se encuentran a su vez recogidos en el ordenamiento colombiano en el Código de Comercio y el Código Civil, tales como: i) Principio de libertad de contratación bajo el cual, las partes "son libres para celebrar un contrato y para determinar su contenido" (UNIDROIT, 2004, Art. 1.1; Código Civil, Art. 16 y 1602; Código de Comercio, Art. 4) ${ }^{42}$; ii) Principio de libertad de forma o de consensualidad, según el cual, y salvo norma expresa en contrario, el contrato se puede probar por cualquier medio y para la realización de un acto, declaración o acuerdo no es necesario recurrir a una solemnidad particular(UNIDROIT, 2004, Art. 1.2; Código de Comercio, Art. 824) ${ }^{43}$; iii) Principio de la buena fe, que impone a las partes la obligación de actuar de manera leal en la actividad negocial (UNIDROIT, 2004, Art. 1.7; Constitución política de Colombia, Art. 83; Código Civil, Art. 769; Código de Comercio, Art. 871$)^{44}$; iv) Principio de comportamiento incoherente, según el cual "una parte no puede actuar en incoherencia con una creencia que ella ha causado a la otra y según la cual esa otra parte ha actuado en su detrimento, fiándose razonablemente y en su desventaja" (UNIDROIT, 2004, Art. 1.8), y, finalmente, v) Principio de los usos y prácticas, que obliga a las partes a respetar cualquier uso en que hayan convenido o cualquier práctica que hayan establecido entre ellas (UNIDROIT, 2004, Art. 1.9).

Finalmente, Espinosa (2007) analiza la incidencia de los medios electrónicos en el campo contractual colombiano, argumentando que la Ley 527 de 1999 no deroga ni modifica los presupuestos de existencia de los contratos (Código de Comercio, Art. 898), estas son las solemnidades sustanciales y los elementos esenciales.

Para el autor, la ley cumplió la función de "ampliar el elenco de oportunidades, medios o alternativas de proposición y conclusión de contratos mercantiles". Así mismo, expone que el sistema jurídico colombiano se orienta al entendimiento del contrato como manifestación relevante de la voluntad de las partes, dando pleno respaldo a sus declaraciones, así como a su libertad de acogerse o no al uso de los medios electrónicos como vehículo de expresión de las mismas.

Concluye, afirmando que en las declaraciones negociales, la ley opta por "presumir" que las partes, si acceden al uso de medios electrónicos, tácitamente han convalidado dichos medios ya que las releva de hacer cualquier clase de declaración previa sobre su empleo en dichas relaciones, por el contrario, lo que exige es manifestación o "acuerdo expreso entre las partes", para que no intervenga en la formación del contrato el empleo de los medios electrónicos a que dicha ley se refiere.

El mismo autor publica un libro titulado: La adaptación del ordenamiento jurídico colombiano a la contratación por medios electrónicos: un análisis desde la perspectiva del derecho comparado (2008), en el cual destaca que la forma y perfeccionamiento del contrato han sumado a sus elementos clásicos o tradicionales, aquellos que implica el haber incorporado a su sistema jurídico interno o local la LMCE.

A su vez, resalta que la exigencia del "papel" por la sola "cultura del papel" es un obstáculo jurídico destinado a la extinción o expulsión de los ordenamientos locales, para que se "oxigene" el esquema contractual con mecanismos de flexibilización mediante la incorporación de principios como el de la equivalencia funcional, el de la neutralidad tecnológica y con dispositivos como el de la firma electrónica reconocida, con el mismo valor de la firma manuscrita, y la extensión de ésta a escenarios como el de la función notarial, de tal suerte que el contrato, en su gestación, 
cumplimiento o ejecución, pueda "respirar" en un entorno altamente tecnológico o digital.

Para Espinosa (2008), la construcción de los medios o instrumentos que permitan establecer las relaciones entre lo particular y lo global implican la búsqueda de valores universales o de categorías o proposiciones que acerquen dichos escenarios, como lo es el principio de libertad de forma de los contratos, sobre el cual pueden construirse marcos jurídicos que armonicen las normas locales con las normas supranacionales sobre formación contractual.

Continúa el autor exponiendo que es preciso realizar una labor armonizadora y unificadora como desafío de los sistemas jurídicos latinoamericanos, con el fin de adaptar sus ordenamientos internos a los modernos modelos de formación contractual a través de medios electrónicos, atacando los obstáculos formales de existencia de los contratos y documentos basados en el clásico soporte papel. Para Espinosa, es preciso encauzar los esfuerzos para conciliar las exigencias tradicionales frente a los equivalentes funcionales fundados en las técnicas electrónicas, pues el futuro:

“está en la integración regional a la actual sociedad global del conocimiento que incluye la inserción de la formación del contrato en un entorno digital, rompiendo la inseguridad en el régimen jurídico aplicable".

El documento (Espinosa, 2008) realiza un amplio estudio en derecho comparado de la institución contractual colombiana en contraste con las normas de la Unión Europea, y especialmente con la normatividad española, en dicho campo, presentado un ejemplo valioso de armonización y unificación, que ha de ser tenido en cuenta en el caso andino.

Finalmente, desde el ámbito gubernamental es necesario resaltar el Plan Nacional de Tecnologías de la Información y las Comunicaciones-PLANTIC-, desarrollado por el Departamento Nacional de Planeación (2008) en el cual se formulan una serie de políticas, acciones y proyectos en ocho ejes principales, cuatro transversales y cuatro verticales, a saber: los ejes transversales (se tratan de aspectos de alto impacto sobre los distintos sectores de la sociedad): 1) Comunidad, 2) Marco regulatorio, 3) Investigación, desarrollo e innovación, y 4) Gobierno en Línea. Los ejes verticales (son programas para la mejor aplicación de las TIC en sectores prioritarios) 1) Educación, 2) Salud, 3) Justicia, y 4) Competitividad empresarial.

El PLANTIC destaca la promulgación de una normatividad sobre comercio electrónico y certificación digital (Ley 527 de 1999 y Decreto 1747 de 2000), con la cual se ha buscado que estas herramientas se usen en estas unidades productivas, pero se muestra consciente que el comercio electrónico y los servicios financieros en línea no se encuentran tan desarrollados en el país.

En consecuencia, plantea como objetivo del PLANTIC el fomento del comercio electrónico en el país a través de incentivos y de la acción coordinada de entidades que lo fomentan, tanto públicas como privadas, que incluya, entre otros, la factura electrónica, la identidad digital y los certificados digitales.

- Perú

La Comisión Multisectorial para masificar el uso de Internet (2001) desarrolló un estudio con el fin de evaluar la situación del Perú respecto de la Sociedad de la Información y plantear líneas de acción que permitan un impulso eficaz del uso de las tecnologías de la información y las comunicaciones. En lo atinente al comercio electrónico, expone que el Perú enfrenta dos problemas significativos, a saber: i) la falta de adaptación a nuevas tecnologías, y ii) la falta de capacidad instalada. Así mismo, explica que la situación económica recesiva del país ha 
limitado o reducido el crecimiento del comercio electrónico. Por otra parte, la población presenta "reticencias" a realizar transacciones en línea, pues la preocupación por la seguridad de los medios de pago es generalizada.

En contraste de lo anterior, se planteó, además de diversos mecanismos de difusión de las ventajas del comercio electrónico, recurrir a las entidades certificadoras para que se divulguen los protocolos de seguridad electrónica, principalmente en los medios de pago, así como la implementación de la "Cámara de Compensación Electrónica", con el fin de integrar el sistema financiero mediante una red interbancaria de tal manera que puedan efectuarse transferencias electrónicas de fondos entre diversas instituciones financieras $y$, finalmente, promover un marco jurídico que permita el empleo de documentos electrónicos con mayor eficiencia y validez, entre ellos los comprobantes de pago electrónicos, que deberán de ser reconocidos por la entidad tributaria.

Así mismo, la Oficina Nacional de Gobierno Electrónico e Informática (2005) desarrolló la estrategia nacional de gobierno electrónico, de la cual se resalta el objetivo de adecuar los procesos de la Administración Pública a los cambios tecnológicos que operan en la sociedad, con el fin de hacerlos más eficientes, transparentes y con enfoque al usuario, lo cual implica una interacción A2B y A2C, mediante la creación de normas y el desarrollo de proyectos que propicien la integración de sistemas de información del Estado, para mejorar la atención a los ciudadanos y ampliar su cobertura.

Finalmente, la mencionada Comisión Multisectorial para el Desarrollo de la Sociedad de la Información (2005) publicó el "Plan de desarrollo de la sociedad de la información en el Perú" en el cual el país se propone "desarrollar el sector social del Perú garantizando el acceso a servicios sociales de calidad, promoviendo nuevas formas de trabajo digno, incentivando la investigación científica e innovación tecnológica, así como asegurando la inclusión social y el ejercicio pleno de la ciudadanía", por medio de la promoción y difusión de nuevas formas de generación de empleo mediante el uso de las TIC, tales como, el teletrabajo, el comercio electrónico, entre otras.

De lo anterior se evidencia el compromiso gubernamental de fomentar el acceso y uso de las tecnologías de la información y las comunicaciones. Sin embargo, se extraña un pronunciamiento acerca de la relación normativa y comercial con los países miembros de la Comunidad Andina.

\section{Conclusiones}

El derecho, en su función reguladora de las relaciones sociales encaminada al mantenimiento de la convivencia dentro de la comunidad, es un elemento determinante dentro de la Sociedad de la Información. Sin embargo, la dinamicidad y especialidad de las manifestaciones que traen consigo las tecnologías de la información y las comunicaciones, obligan al operador jurídico a formular políticas y normas que contrarresten las inquietudes y vicisitudes que minan la seguridad jurídica de los ordenamientos jurídicos.

La labor de UNICTRAL, mediante la formulación de la Ley Modelo de Comercio Electrónico, ha sido fundamental en los últimos años. A nivel andino, los países han declarado abiertamente su compromiso de constituir como objetivos comunes el garantizar el acceso de la población a los servicios de telecomunicaciones y establecer normas que doten de seguridad las diferentes fases de las operaciones comerciales que utilizan recursos electrónicos.

Sin embargo, la situación comunitaria no es alentadora. En primer lugar, a pesar de que la mayoría de los países miembros poseen reglamentación vigente sobre el tema (la Ley 
aprobada para tal fin en Bolivia está, a la fecha, pendiente de sanción y promulgación), las tendencias, orientaciones y disposiciones son divergentes, creando la existencia de una "inseguridad jurídica" en el tema.

Por otra parte, tal y como se puede comprobar en los estudios nacionales, la regulación estatal acusa el problema de establecer un sistema de normas que atienda una necesidad particular e individual, una necesidad nacional, bajo un esquema de espacio-tiempo limitado, dejando de lado la internacionalidad, como elemento sustancial y característica inherente al comercio electrónico.

De acuerdo con lo anterior, el carácter internacional conduce a formular un tratamiento jurídico más conveniente, que elimine la disparidad de los ordenamientos nacionales a través de la armonización o la unificación normativa, en el entendido que este nuevo marco jurídico reconocerá la vocación internacional y lo cambiante de las situaciones particulares propias del comercio electrónico.

Así mismo, las dificultades y obstáculos, en términos de comercio electrónico en la región incluyen temas políticos, técnicos y jurídicos, sin embargo, para efectos de la investigación propuesta se abordarán, con mayor profundidad, los problemas legales, dentro de los cuales se evidencia la necesidad de establecer un marco jurídico armónico, claro, sencillo y compatible con las normas vigentes a escala internacional, siguiendo el ejemplo de la Unión Europea, caracterizado por proponer herramientas de protección al consumidor, de seguridad en las transacciones, no discriminatorio, que fomente la expansión del acceso a las tecnologías de la información y de las telecomunicaciones, en pocas palabras, un derecho y una jurisdicción aplicable de forma unificada.

Ahora bien, la cuestión del derecho aplicable a las diferentes relaciones jurídicas en el entorno electrónico no es nueva, es más, presenta ya diferentes teorías o posturas que oscilan entre la no regulación y la estatización del derecho electrónico, pasando por tendencias como la autorregulación, y la internacionalización de las normas, siendo estas últimas dos las más sustentadas.

Respecto de la autorregulación, como mecanismo de normalización del comercio electrónico, se plantea la dificultad de lograr una forma generalizada en un marco tan heterogéneo, además porque no "combate" la desconfianza, la falta de seguridad y protección al consumidor como dificultades inherentes al e-commerce en el ambiente comunitario.

Pero no todos los postulados de quienes defienden la autorregulación son criticables, por el contrario, no queda más que destacar y reiterar que las instituciones legales, especialmente en el ámbito mercantil, encuentran su origen en los usos y prácticas de los comerciantes, el legislador debe concentrarse en dotar de estabilidad, certeza y generalidad las bases dictadas por la praxis social.

La "búsqueda" de una normatividad andina común, respecto de la contratación por medios electrónicos, parece haberse quedado en pronunciamientos, políticas, objetivos o finalidades, pues a pesar del esfuerzo que, desde la Conferencia Especializada Internacional sobre Derecho Internacional Privado -CIDIP-, ha realizado la Organización de Estados Americanos, y algunas misiones permanentes para este organismo, el incipiente estado de desarrollo tecnológico en América Latina y el Caribe obliga a las políticas estatales a decaer u ocuparse en los problemas básicos de infraestructura, en oposición al debate que, principalmente en Europa y Estados Unidos, se ha centrado en temas avanzados como la privacidad y confianza del consumidor y la legalidad de las actividades digitales.

Por otra parte, diversos autores resaltan la necesidad de armonizar o unificar la 
normativa respecto del entorno digital, de establecer principios y medidas que permitan dotar de seguridad jurídica a los actores de las relaciones electrónicas, en otras palabras, es preciso encauzar los esfuerzos para conciliar las exigencias tradicionales frente a los equivalentes funcionales fundados en las técnicas electrónicas, porque el futuro está en la "integración regional" al amparo de la actual sociedad global del conocimiento.

Sin embargo, es evidente que no se han determinado los elementos normativos que posibiliten la unificación a nivel de la Comunidad Andina, como un mecanismo de competitividad al interior de la comunidad económica mundial.

La necesidad actual de América Latina, obviamente, no se restringe a los cuatro países miembros de la CAN, por lo que es preciso ser conscientes de una eventual globalización jurídica, razón por la cual el diseño de normas tiene que realizarse dentro de parámetros y principios que permitan su posterior compatibilización, de tal forma que, en el futuro, se pueda contar con una regulación suramericana (con la unión de la CAN y el Mercosur) del comercio electrónico con base en la convergencia normativa de estos dos procesos de integración.

\section{Notas}

1 Para Gómez Segade, caracterizar al comercio electrónico como la realización electrónica de transacciones comerciales no representa novedad y mucho menos modernidad, pues desde hace ya más de 25 años las entidades financieras realizan intercambios de información por medios electrónicos, en lo que el autor denomina el comercio electrónico embrionario (limitado a las relaciones B2B, esto es entre empresarios).Continúa Gómez argumentando que lo característico del comercio electrónico moderno es la existencia de una infraestructura mundial de tecnologías que permite la vinculación a la red de múltiples actores, lo que permite un ambiente fluido $\mathrm{y}$ altamente variado, pues permite tanto la realización de transacciones comerciales, como el desarrollo de actividades anteriores o posteriores al negocio jurídico, tales como la publicidad, la búsqueda de información, la oferta, la atención posventa, entre otras. (Gómez, 2001, págs. 25 a 28). Por otra parte, el literal b) del artículo 2 de la Ley 527 de 1999, por medio de la cual se define y reglamenta el acceso y uso de los mensajes de datos, del comercio electrónico y de las firmas digitales, y se establecen las entidades de certificación y se dictan otras disposiciones, la cual publicada el 21 de agosto de 1999 en el Diario Oficial N. ${ }^{\circ}$ 43.673, expone que el comercio electrónico comprende las "cuestiones suscitadas por toda relación de índole comercial, sea o no contractual, estructurada a partir de la utilización de uno o más mensajes de datos o de cualquier otro medio similar". Sobre la noción y antecedentes del concepto de "comercio electrónico" ver también: (Sandoval, 2003, págs. 15 a 20; Lorenzetti, 2003, págs. 68 a 69).

2 Para Galgano (2005, págs. 105 a 112), las concepciones clásicas del derecho no ubican al contrato entre las fuentes normativas. Sin embargo, continuar concibiendo el contrato como mera aplicación del derecho, y no como una fuente del nuevo derecho, implica no comprender de qué modo cambia el derecho de nuestro tiempo. "Las diversas autodisciplinas contractuales, a las que la ley hace referencia cada vez con mayor frecuencia, defienden una serie importante de intereses generales. Éste es el caso de los códigos de comportamiento, o deontológicos, redactados por asociaciones de categorías o por sociedades de gestión de mercados reglamentados, receptados por el nuevo artículo 2387 del código civil (italiano)".

El artículo 2387 del nuevo Código Civil Italiano, en su parte pertinente, expresa que los estatutos (de la sociedad anónima) podrán formular las exigencias de honorabilidad, profesionalidad y la independencia del 
administrador para la celebración de contratos, también, con referencia a estos requisitos, podrá resguardarse en los códigos de conducta elaborados por asociaciones comerciales o por las sociedades de gestión de los mercados regulados. "Lo statuto può subordinare l'assunzione della carica di amministratore al possesso di speciali requisiti di onorabilità, professionalità ed indipendenza, anche con riferimento ai requisiti al riguardo previsti da codici di comportamento redatti da associazioni di categoria o da società di gestione di mercati regolamentati”.

3 Uniform Rules and Guidelines for Electronic Trade and Settlement (URGETS).

${ }^{4}$ Para los efectos de este trabajo, las expresiones e-business y e-commerce son equivalentes al término 'comercio electrónico'.

5 Sobre la seguridad jurídica, se han planteado diversas definiciones que se encuentran altamente ligadas a la línea de pensamiento de cada autor o filósofo del Derecho. Por ejemplo, para Radbruch (1947, pág. 40), la seguridad jurídica es conferida por el Derecho mismo, al garantizar la vida y bienes de las personas, siempre que se sujete a cuatro condiciones a saber: i) que el Derecho se halle estatuido en leyes; ii) que el Derecho se base en hechos y que no se remita a los juicios de valor del juez; iii) que los hechos en que se basa el Derecho sean practicables, y iv) finalmente, el Derecho no debe hallarse expuesto a cambios demasiados frecuentes. Es evidente que la definición de 'seguridad jurídica', formulada por el autor reseñado, está relacionada con una tendencia marcadamente formalista del Derecho.

Para Kelsen (1995, pág. 260), el principio de seguridad jurídica deriva en la previsibilidad de las decisiones de los tribunales, que sirve a los destinatarios del derecho para orientar su comportamiento. En este mismo sentido, Corte Constitucional (Cifuentes, Martínez y Naranjo, 1995, A.V. C-194 Mag).
Ahora bien, para la Corte Constitucional Colombiana, el principio de seguridad jurídica implica, entre otras, formas o efectos, la confianza del conglomerado social en lo resuelto, sin que surjan nuevas acciones que provoquen la indefinida reanudación de procesos. Ver: Corte Constitucional (1992, C-543; 2001, SU-014).

${ }^{6}$ El concepto de "lex retialis" es apropiado de Olivera (2008, pág. 8) quien lo utiliza como recurso metodológico para hacer referencia al nuevo derecho de carácter global ("ley de la red") que, al estilo de la lex mercatoria, busca el ordenamiento de la Sociedad de la Información.

${ }^{7}$ El Grupo de trabajo IV de la Comisión de Naciones Unidas para el Derecho Mercantil Internacional (CNUDMI o UNCITRAL), encargado específicamente de los aspectos relativos al comercio electrónico, ha realizado diversas sesiones de trabajo, de las cuales han publicado diferentes evidencias y documentos de estudio disponibles en: http://www.uncitral. org/uncitral/es/commission/working-groups/4 Electronic_Commerce.html

${ }^{8}$ En este punto se hace referencia a la Ley del Estado de Utah sobre Firma Digital ("Utah Digital Signature Act", del 1 de mayo de 1995), la cual está estrechamente vinculada con la Guía de Firma Digital (Digital Signature Gidelines), publicada en octubre de 1995 por The American Bar Association's Information Security Committee (Comité de la ABA Science and Technology section).

9 El Centro de Promoción Bolivia (CEPROBOL), institución que adelanta el Programa Boliviano de Comercio Electrónico, presta asesoría a las empresas para la implementación de medios electrónicos en el desarrollo de su objeto social propio, así como un seguimiento a la normatividad sobre la materia, en donde se constata que, a la fecha de presentación de este documento, existe normatividad aprobada por el $\mathrm{H}$. Congreso 
Nacional de Bolivia, más no hay registro de haber sido sancionada o promulgada. El proyecto se denominó: "Ley de documentos, firmas y comercio electrónico" (Proyecto de Ley N. ${ }^{\circ} 080$ de 2007). De acuerdo con lo anterior, y dados los procedimientos para la expedición de leyes, es válido afirmar que a la fecha de este documento el proyecto se encuentra en trámite. La última consulta a CEPROBOL se realizo el día 25 de enero de 2009, y la última actualización existente respecto del proyecto de ley en mención es del mes de marzo de 2008. Así mismo, se consultó la página web del $\mathrm{H}$. Congreso Nacional de Bolivia (www.congreso. gov.bo) y no se encontró registro sobre el mismo.

La normatividad Boliviana sobre el descriptor "comercio electrónico" hace referencia a la creación de la Agencia para el Desarrollo de la Sociedad de la Información en Bolivia (ADSIB) en el año 2002 (Decreto Supremo 26553), así como a la regulación de los nombres de dominio (Decreto Supremo 26624) del mismo año.

${ }^{10}$ Sobre el nuevo concepto de documento desde la perspectiva de los medios electrónicos: Vid. Espinosa Quintero (2008).

11 Siguiendo lo expresado por Bulla Quintana (2008, pág. 232), investigar es la actividad encaminada al descubrimiento de conocimientos nuevos en el campo de las ciencias, de las artes y de las letras. La actividad investigativa es el trabajo que se realiza para descubrir algo que no se conocía. Considera la investigación en un doble sentido: i) amplio, cuando se dirige a realidades ya conocidas, ya sea para conocerlas mejor o para interpretarlas $\mathrm{u}$ organizarlas en una forma novedosa; ii) estricto, cuando descubre realidades, relaciones o procesos nuevos.

${ }^{12}$ A la fecha, la Comunidad Andina está conformada, únicamente, por cuatro países miembros (Bolivia, Colombia, Ecuador y Perú), cinco países asociados (Argentina,
Chile, Brasil, Paraguay y Uruguay) y dos países observadores (México y Panamá). La calidad de país asociado se determina mediante Decisión del Consejo Andino de Ministros de Relaciones Exteriores, y concede al país beneficiario la posibilidad de intervenir en las reuniones de los órganos comunitarios y, en el caso de Chile, establecer comisiones de trabajo conjunto en temas de mutuo interés para lograr acuerdos de normatividad común.

Venezuela denunció oficialmente el Tratado de la Comunidad Andina (Acuerdo de Cartagena) el 22 de abril de 2006.

13 Para Illescas y Perales (2003, pág. 28), la corriente de internacionalización logra la conformación de un Derecho Uniforme del Comercio Internacional (DUCI), entendido como un conjunto de normas del ordenamiento jurídico que regulan los problemas específicos del tráfico económico internacional de las empresas. Así mismo, señalan que existen otras denominaciones no tan acertadas para este conjunto de normas como derecho mercantil internacional, derecho comercial internacional, derecho del comercio internacional o lex mercatoria. Ver también: (Fernández, 2007, págs. 45 a 49; Oviedo, 2001)

${ }^{14}$ Para Bulla Quintana (2008, págs. 248 a 250) la comprobación mediante procedimientos inductivos acarrea cuatro etapas a saber: i) la observación de los hechos y fenómenos particulares; ii) la hipótesis o explicación provisional de un hecho; iii) la experimentación o verificación de la hipótesis; y iv) la generalización de la hipótesis comprobada.

${ }^{15}$ La presente investigación se vale de la razón, mas no de la experimentación, y pretende la formulación de conclusiones dependientes de un análisis lógico-racional.

16 Los argumentos de autoridad, en oposición al método científico, se fundan en el valor intelectual o moral de quien algo sostiene. 
17 El método de investigación, o heurístico, propende buscar, inventar o hallar lo que se desconoce.

${ }^{18}$ Herrera (2006) explica que las fuentes de conocimiento son todo el material que puede ser objeto del análisis y del cual se puede extraer información jurídicamente relevante desde el punto de vista científico. Son materiales que entregan al investigador información sobre hechos jurídicos relevantes. En particular enuncia las siguientes: normas jurídicas, sentencias, opiniones de la doctrina, conductas, formas de lenguaje, estadísticas, registros, mapas, fórmulas, documentos, etc.

${ }^{19} \mathrm{La}$ crítica externa de las fuentes está encaminada a verificar la autenticidad o validez de los documentos, es un examen formal de la fuente de contenido. Por su parte, la crítica interna de las fuentes se orienta a determinar el significado y la confiabilidad de los datos que contiene el documento, es un estudio sustancial o material de la información.

${ }^{20} \mathrm{La}$ interdisciplinariedad nace como reacción ante la excesiva especialización de la ciencias, y se inspira en la articulación de las disciplinas particulares y de los diversos sectores de afinidad, para que en una síntesis conciliatoria se articulen las disposiciones curriculares y los esfuerzos de investigación de tal forma que se formulen mejores y más armónicas soluciones a los problemas que se plantean en el mundo moderno.

Sobre el análisis de la palabra 'interdisciplinariedad', así como sus modalidades: Vid. Borrero (1984, págs. 68 a 72) y Torres (1994, pág. 65).

En este estudio, Borrero expone que el concepto de interdisciplinariedad da cuenta de dos "formas falsas" de presentación, estas son: i) la multidisciplinariedad (definida como la yuxtaposición, sin articulación ni relación, de diversas disciplinas), y ii) la pluridisciplinariedad (entendida como una forma de multidisciplinariedad, que se caracteriza porque una disciplina sobresale entre las demás).

De lo anterior se puede colegir que, el concepto de interdisciplinariedad, no se limita a una yuxtaposición de ciencias, sino que por el contrario requiere, inevitablemente, la relación armónica de contenidos, métodos y conclusiones de las demás ciencias.

${ }^{21}$ Sobre la importancia de la empresa en el mundo globalizado: Vid. Galgano (2005, pág. 35), Fernández Rozas (2007, pág. 28), Instituto Colombiano para el Desarrollo de la Ciencia y la Tecnología (2008).

22 El término ventajas cooperativas se extracta de la propuesta de Vessuri (2008, pág. 80 a 84), quien, respecto de las Tendencias de la Educación Superior, afirma que debido a la digitalización, las nuevas tecnologías, la globalización, ha surgido la investigación y la innovación en cooperación, que ya genera, organiza y usa el conocimiento en una cantidad de formas nuevas. Continúa Vessuri afirmando que las ventajas cooperativas se están convirtiendo en un componente fundamental en un mundo que cada vez está más interconectado.

Por su parte, Zarur Miranda (2008, pág. 231), expone que para las personas que trabajan en el ámbito académico, educativo y universitario es claro que la mejor manera de actuar es mediante la creación de redes, pues es preciso juntar las fortalezas de cada institución para superar las debilidades.

23 Vid. Moncayo (2004, pág. 132) y Galgano (2005, pág. 35)

${ }^{24}$ La Ley 527 del 21 de agosto de 1999 se publicó en el Diario Oficial No. 43.673 del 21 de agosto de 1999.

${ }^{25}$ El Decreto 1747 del 11 de septiembre de 2000 se publicó en el Diario Oficial No. 44.160 del 14 de septiembre de 2000 .

${ }^{26}$ Esta ley se publicó en el Registro Oficial Suplemento No. 557 del 17 de abril del 2002. 
${ }^{27}$ Este decreto se publicó en el Registro Oficial Suplemento No. 735 del 31 de diciembre del 2002.

${ }^{28}$ La Ley No. 27269 publicada en el diario oficial El Peruano del día 28 de mayo de 2000.

29 La modificación al Código Civil incorpora la posibilidad de realizar manifestaciones de voluntad expresa mediante un medio electrónico o cualquier otro análogo. Así mismo, se consagra que cualquier exigencia legal de formalidad puede satisfacerse a través de medios electrónicos, ópticos o cualquier otro análogo.

La Ley No. 27291, publicada en el diario oficial El Peruano del día 17 de junio de 2000.

30 La Revista de la Contratación Electrónica, publicada por la Editorial EDICIP (Madrid, España) posee como materia de estudio la contratación informática y el comercio electrónico. Disponible en: [http:// v2.vlex.com/es/ppv/doctrina/fuente_59].

31 La Asociación Latinoamericana de Integración (ALADI) es un organismo de integración económica intergubernamental de América Latina, creado mediante el Tratado de Montevideo suscrito el día 12 de agosto de 1980, y al cual pertenecen Argentina, Bolivia, Brasil, Chile, Colombia, Cuba, Ecuador, México, Paraguay, Perú, Uruguay y Venezuela. Más información: [http://www.aladi.org/nsfaladi/ estudios. nsf/inicio2004].

${ }^{32}$ El documento estudia, entre otros, los siguientes bloques de integración regional: NAFTA (Tratado de Libre Comercio entre Estados Unidos, Canadá y México), CAFTA-DR (Tratado deLibre Comercio entre Estados Unidos, Centroamérica y República Dominicana), CARICOM (Comunidad del Caribe), CAN (Comunidad Andina), MERCOSUR (Mercado Común del Sur), UE(Unión Europea), ECOWAS (Comunidad Económica de Estados de África Occidental), ASEAN (Asociación de Naciones del Sureste Asiático).
33 El estudio (ALADI, 2007) resalta la necesidad de implementar programas de promoción en el uso de TIC en los siguientes sectores: empresarial, educación y gubernamental. Así mismo, se recomienda la creación de Agendas de Conectividad comunes con el fin de lograr la integración de los países en el sector telecomunicaciones.

${ }^{34}$ La Conferencia Especializada Interamericana sobre Derecho Internacional Privado son convocadas por la Organización de Estados Americanos (OEA) por medio de la Secretaría de Asuntos Jurídicos con el fin de ayudar y apoyar la armonización y codificación del Derecho Internacional Privado en el Hemisferio Occidental. Más información: [http://www.oas. org/DIL/esp/derecho_internacional_privado_ confe-rencias.htm].

${ }^{35}$ Según lo planteado por Dreyzin (2005), la autorregulación es defendida por aquellos que consideran que la red debería estar gobernada por los propios usuarios. Sobre este particular, continúa la autora afirmando que el pretendido carácter consensual de las normas elaboradas por los interesados encuentra una barrera en la dificultad de lograrse en forma generalizada en un marco tan heterogéneo, más aún si se tiene en cuenta que la desconfianza y la falta de seguridad y protección al consumidor son dificultades generalizadas en el ámbito del e-commerce.

${ }^{36}$ En la actualidad, el comercio electrónico no se restringe a tratos entre comerciantes sino que, por el contrario, se extiende a una gran variedad de relaciones jurídicas. La forma tradicional de clasificar el comercio electrónico, según los agentes que intervienen en el mismo, implica asignar letras a cada una de las partes (Administración -A-, las empresas -B- y los consumidores $-\mathrm{C}-$ ), extractando una amplia gama de posibilidades, a saber: A2A, A2B, A2C, B2B, C2C.

${ }^{37}$ La Cámara de Comercio Internacional (CCI) es una organización empresarial con 
personalidad jurídica propia y naturaleza asociativa, que representa mundialmente los intereses empresariales, se constituyó en París en 1919 y continúa teniendo su sede social en la capital francesa. Sus fines estatutarios básicos son actuar a favor de un comercio abierto y crear instrumentos que lo faciliten, así mismo, defiende la globalización de la economía como una fuerza para el crecimiento económico, la creación de trabajo y la prosperidad, en tanto las economías nacionales son cada vez más interdependientes, y por ello, las decisiones gubernamentales tienen repercusiones internacionales más fuertes que en el pasado. Más información en: http://www.iccwbo.org/

${ }^{38}$ Los e-terms publicados por la CCI en el año 2004 poseen el siguiente tenor:

"A. Article 1 - E-commerce agreement

The parties agree:

1.1 that the use of electronic messages shall create valid and enforceable rights and obligations between them; and

1.2 that to the extent permitted under the applicable law, electronic messages shall be admissible as evidence, provided that such electronic messages are sent to addresses and in formats, if any, designated either expressly or implicitly by the addressee; and

1.3 not to challenge the validity of any communication or agreement between them solely on the ground of the use of electronic means, whether or not such use was reviewed by any natural person.

\section{A. Article 2 - Dispatch and Receipt}

2.1 An electronic message is deemed 1 to be:

(a) dispatched or sent when it enters an information system outside the control of the sender; and

(b) received at the time when it enters an information system designated by the addressee.

2.2 When an electronic message is sent to an information system other than that designated by the addressee, the electronic message is deemed to be received at the time when the addressee becomes aware of the message.
2.3 For the purpose of this contract, an electronic message is deemed to be dispatched or sent at the place where the sender has its place of business and is deemed to be received at the place where the addressee has its place of business".

${ }^{39}$ Es evidente que Umaña manifiesta una clara tendencia autorregulatoria, en términos similares a los señalados por Dreyzin (2005) para esta teoría.

40 En ese mismo sentido: Menéndez (2005).

41 El Instituto Internacional para la Unificación del Derecho Privado (UNIDROIT) es una organización intergubernamental independiente con sede en Roma, creada con el objetivo de estudiar las necesidades y métodos para modernizar, armonizar y coordinar las legislaciones privadas $\mathrm{y}$, en particular, el derecho comercial entre los Estados y grupos de Estados, con el fin de lograr una normatividad de derecho privado uniforme. En Colombia los estatutos de la UNIDROIT se incorporaron a su sistema jurídico mediante la Ley 32 de 1992.

${ }^{42}$ Sobre la autonomía de la voluntad y la libertad contractual: Oviedo (2008, págs. 93-94; 2005, pág. 28); Espinosa (2008, pág. 204); Gual (2008, págs. 218-222); De Miguel (2007, pág. 247); Pájaro (2006, págs. 52-53); Castellanos (2006, págs. 56-57); López (2006, págs. 119-122); Galgano (2005, págs. 64-81); Chuliá (2005, págs. 79-80); Fernández (2003, pág. 11); Noguera (2002, pág. 217); Ravassa (2002, pág. 276); Emiliani (2001, pág. 59); Corte Constitucional (2000, C-529); Bobbio (1997, pág. 69); Reale (1982, pág. 137)

${ }^{43}$ Respecto del principio de consensualidad, Ver: Espinosa (2008, pág. 215); Emiliani (2001, pág. 61); Corte Suprema de Justicia (2000, sala de casación civil, Ex pág. 5397; 1981, sala de casación civil, GJ N. ${ }^{\circ}$ 2407). 
${ }^{44}$ Sobre el principio de buena fe contractual: Solarte (2008, pág. 114); Estigarribia (2008, pág. 211); Industria y Comercio (2003); Valencia (1981, pág. 196): Suescún Melo, J. (1996, pág. 18); Corte Constitucional (1994, C-544; 1995, C-540; 2002, C-423; 1996, C-253).

${ }^{45}$ Sobre este particular, se rescata que el Decreto 1929 de 2007 faculta a los empresarios a expedir la factura electrónica como un documento equivalente a la factura física, que soporta transacciones de venta de bienes y que para efectos fiscales debe ser expedida, entregada, aceptada y conservada por y en medios y formatos electrónicos. Así mismo, el 17 de junio de 2008 el legislador colombiano, mediante la Ley 1231 de julio de 2008, desarrolla un marco normativo para la factura como titulo valor, incluida la factura electrónica, para lo cual delega en el Gobierno su reglamentación. Más información ver: Ríos (2007).

\section{Referencias}

Araoz M. \& Van Ginhoven, S. (2001) Preparación de los países andinos para integrar las redes de tecnologías de la información. Universidad del Pacífico. [Disponible en: http://74.125.47.132/ search?q=cache:SKWlwa4ySKAJ:www. cid.harvard.edu/archive/andes documents /workingpapers/it/it_peru.pdf+Preparaci on $+\mathrm{de}+$ los + paises + andinos + para + integra $\mathrm{r}+$ las + redes + de + tecnologias + de + la + info rmacion $\& \mathrm{hl}=\mathrm{es} \& \mathrm{ct}=\mathrm{clnk} \& \mathrm{~cd}=3 \& \mathrm{gl}=\mathrm{co}]$.

Asociación Latinoamericana de Integración (2001). Situación actual y perspectivas del comercio electrónico en la región. [Disponible en: http://www.aladi.org/ nsfaladi/reuniones.nsf/ceb8a0c5450bdab 803256a79004f67cc/4ea21444af6077b1 03256a790050e7ad?OpenDocument].

Asociación Latinoamericana de Integración (2007). Estudio comparado sobre la definición y consideración de los temas vinculados a las Tecnologías de la Información y las Comunicaciones (TIC) en otros esquemas de integración regional. [Disponible en: http://www. aladi.org/nsfaladi/integracion.nsf/eeeed 45 bc6cbdcf7032574fd00627b37/a70042497 1590eed032574b900470f5f?OpenDocum ent].

Bobbio, N. (1997) Teoría general del Derecho. Temis.

Borrero, A. (1984). La interdisci-plinariedad. Simposio Permanente sobre la Universidad - Segundo Seminario General. Asociación Nacional de Universidades (ASCUN) e Instituto Colombiano para el Fomento de la Educación Superior (ICFES).

Bulla Quintana, R. (2008). Nociones preliminares de lógica. Bogotá D.C., Universidad Sergio Arboleda.

Calderón Rodríguez, C. (2000). "El Comercio electrónico: Nueva Lex mercatoria del Comercio Internacional". Revista de Derecho Informático Alfa Redi [Disponible en: http://www.alfa-redi.org/ rdi-articulo.shtml? $\mathrm{x}=553$ ].

Cárdenas Zorro, M.J. (2000). E-comercio andino. Portafolio. [Disponible en: http:// www.comunidadandina.org/prensa/ articulos/porta27-6-00.htm].

Castellanos Ruiz, E. (2005). Autonomía conflictual y contratos internacionales. In (cap. Cuestiones actuales sobre el derecho mercantil internacional). Colex.

Castellanos Ruiz, E. (2006). Lex mercatoria y autonomía privada en materia de contratos internacionales. In (cap. Nueva lex mercatoria y contratos internacionales). Ibáñez. 
Cibertribunal Peruano, (2008). [Disponible en: http://www.cibertribunalperuano.org/ portalcibertribunal/Principal.aspx].

Comisión de Naciones Unidas para el Derecho Mercantil Internacional - CNUDMI(1996). Guía para la incorporación de la Ley Modelo de la CNUDMI sobre Comercio Electrónico. [Disponible en: http://www.uncitral.org/pdf/spanish/texts/ electcom/05-89453_S_Ebook.pdf].

Comisión Multisectorial para el Desarrollo de la Sociedad de la Información (2005). Plan de desarrollo para la Sociedad de la Información en el Perú. Agenda digital peruana. Oficina Nacional de Gobierno Electrónico e Informática. Presidencia del Consejo de Ministros. Perú. [Disponible en: http://www.peru.gob.pe].

Comisión Multisectorial para el Desarrollo de la Sociedad de la Información (2001) E-Perú: Propuestas para un plan de acción para el acceso democrático a la sociedad global de la información y el conocimiento. Ministerio de Transportes, Comunicaciones y Vivienda. [Disponible en: http://www.colombiadigital.net/ informacion/ docs/eperu.pdf].

Comunidad Andina (2000). Documento de Lima sobre la Sociedad Global de la Información. Comunidad Andina .

Corte Constitucional (1992). Sentencia C-543. M.P. José Gregorio Hernández Galindo.

Corte Constitucional (1993). Sentencia C-486. M.P. Eduardo Cifuentes Muñoz.

Corte Constitucional (1994). Sentencia C-544. M.P. Jorge Arango Mejía.

Corte Constitucional (1995). Sentencia C-540. M.P. Jorge Arango Mejía.

Corte Constitucional (1995). Aclaración de Voto Sentencia C-194. Mags. Cifuentes
Muñoz, E.; Martínez Caballero, A. y Naranjo Mesa, V.

Corte Constitucional (1996). Sentencia C-253. M.P. Hernando Herrera Vergara.

Corte Constitucional (2000). Sentencia C-529. M.P. Antonio Barrera Carbonell.

Corte Constitucional (2001). Sentencia SU-014. M.P. Martha Victoria Sáchica Méndez.

Corte Constitucional (2002) Sentencia C-423. M.P. Álvaro Tafur Galvis.

Corte Suprema de Justicia (1981). Sala de Casación Civil. Gaceta Judicial N. ${ }^{\circ} 2407$.

Corte Suprema de Justicia (2000). Sala de Casación Civil. Exp. 5397.

Cumbre Mundial sobre la Sociedad de la Información (2004). Declaración de principios. Cumbre Mundial sobre la Sociedad de la Información [Disponible en: http://www.itu.int/wsis/geneva/indexes.html].

Chuliá, F. (2005). Introducción al Derecho mercantil. Tirant lo Blanch.

De Miguel Asensio, P.A. (2007). Contratación Comercial Internacional. In (cap. Derecho de los negocios internacionales). Iustel.

Departamento Nacional de Planeación (2006). Visión Colombia II Centenario: 2019. República de Colombia. [Disponible en: http://www.dnp.gov.co/PortalWeb/ Políticas deEstado/VisiónColombia2019/ Documentos2019/tabid/775/Default.aspx].

Dreyzin de Klor, A. (2005) Derecho aplicable al comercio electrónico. In (cap. Nueva lex mercatoria y contratación). Globalización y Derecho privado (Col.). [Disponible en: http://www.buscalegis.ufsc.br/arquivos/ derecho\%20aplicable.pdf]. 
Emiliani Román, R. (2001) Curso Razonado de las obligaciones. Universidad Sergio Arboleda.

Espinosa Quintero, L. (2007). Incidencia de los medios electrónicos en el campo contractual colombiano. Revista Civilizar. Universidad Sergio Arboleda. [Disponible en: http://www.usa.edu.co/ civilizar/incidencia_medios.htm]

Espinosa Quintero, L. (2008). La adaptación del ordenamiento jurídico colombiano a la contratación por medios electrónicos: un análisis desde la perspectiva del derecho comparado. Universidad Sergio Arboleda.

Estigarribia Bieber. M.L. (2008). La buena fe. Implicaciones actuales en las relaciones negociales. (In cap. Derecho privado y globalización. Tomo III. Contratos). Ibáñez.

Fernández Rozas, J.C. (2000). El derecho del comercio internacional en el contorno de la globalización. Revista del colegio de Notarios del Estado de México.

Fernández Rozas, J.C. (2004). Ius mercatorum. Autorregulación y unificación del derecho de los negocios transnacionales. Consejo General del Notariado.

Fernández Rozas, J.C. (2007). Derecho de los Negocios internacionales. In (cap. Derecho de los negocios internacionales). Iustel.

Galgano, F. (2005) La globalización en el espejo del derecho. Santa Fe, Argentina: Rubinzal-Culcioni.

Gómez Segade, J.A. (2001). Comercio Electrónico en Internet. In (chap. El comercio electrónico en la sociedad de la información). Marcial Pons.
Gorena Belling, L.F. (2004) La legislación del comercio electrónico de los servicios profesionales en la Comunidad Andina. Biblioteca Digital Andina. Universidad Andina Simón Bolívar de Bolivia. [Disponible en: http://www. comunidadandina.org/BDA/docs/BOINT-0002.pdf].

Gual Acosta, J, M. (2008) Clausulas de exoneración y limitación de responsabilidad civil. Ibáñez.

Herrera, E. (2006). Práctica metodológica de la investigación jurídica. Astrea.

Hilbert, M.; Bustos, S. y Ferrat, J.C. (2003). Estrategias nacionales para la sociedad de la información en América Latina y el Caribe. Comisión Económica para América Latina y el Caribe -CEPAL- [Disponible en: http:/www.eclac.org/publicaciones/ $\mathrm{xml} / 5 / 13815 /$ Estrategias.pdf].

Illescas Ortiz, R.; Perales Viscasillas, P. (2003). Derecho Mercantil Internacional. El Derecho Uniforme. Universidad Carlos III de Madrid. Ramón Areces.

Instituto Colombiano para el Desarrollo de la Ciencia y la Tecnología -Colciencias(2008). Colombia Construye y Siembra Futuro. [Disponible en: http://www. colciencias.gov.co/portalcol/downloads/ archivosContenido/632.pdf].

Instituto Internacional para la Unificación del Derecho privado - UNIDROIT - (2004) Principios UNIDROIT sobre los contratos comerciales internacionales. [Disponible en:http://www.unidroit.org/spanish/ principles/contracts/principles2004/ blackletter2004.pdf].

Iriarte Ahon, E. (2003). Informe sobre Comercio electrónico en America Latina. Monitor de políticas TIC en América 
Latina y el Caribe. [Disponible en: http://lac.derechos.apc.org/investigacion/ comercio_electronico.doc].

Iriarte Ahon, E. (2005). Sociedad de la Información: Políticas y Regulación en America Latina y el Caribe ¿hacia donde vamos los profesionales en Derecho y Nuevas Tecnologías?. Revista de derecho informatico Alfa-Redi. [Disponible en: http://www.alfa-redi.org/rdi-articulo. $\operatorname{shtml} ? \mathrm{x}=3917]$.

Iriarte Ahon, E. (2006). Comercio Electrónico en América Latina: Realidades y Perspectivas. Monitor de políticas TIC en América Latina yel Caribe. [Disponible en: http://lac.derechos.apc.org/investigacion/ comercio_electronico-1.pdf].

Jijena Leiva, R.J. (2006). Documentos, Firmas Electrónicas y Entidades Certificadoras: Contenido y Alcances de un Proyecto de Ley para Bolivia. Revista de Derecho Informático Alfa Redi. [Disponible en: http://www.alfa-redi.org/rdi-articulo. shtml? $x=6506]$.

Katz, J.M. \& Hilbert, M. (2003). Los caminos hacia una sociedad de la información en América Latina y el Caribe. Comisión Económica para América Latina y el Caribe -CEPAL-. [Disponible en: http://www.cepal.cl/publicaciones/xml/ 9/12899/lcg2195e2.pdf].

Kelsen, H. (1995). Teoría pura del Derecho. Porrúa.

Laguna Quiroz, R. (2005). El trabajo en la era digital: análisis de la relación contractual. Revista de Derecho Informático Alfa Redi. [Disponible en: http://www.alfaredi.org/rdi-articulo.shtml? $\mathrm{x}=986]$.

López Rodríguez, A.M. (2006). Las compilaciones orgánicas de principios generales del derecho de los contratos y su naturaleza jurídica. In (cap. Nueva lex mercatoria y contratos internacionales). Globalización y derecho (Col.). Ibáñez.

Lorenzetti, R.L. (2003). Comercio Electrónico. In (chap. El comercio electrónico. La teoría general). Temis y ARA Ediciones.

Menéndez Mato, J.C. (2005) El contrato vía Internet. Bosch.

Ministerio de Comunicaciones (2008). Plan Nacional de Tecnologías de la Información $y$ las Comunicaciones. República de Colombia. [Disponible en: http://www. colombiaplantic.org/docs/Plan_tics.htm].

Misión Permanente de Estados Unidos de América ante la Organización de Estados Americanos (2002). Proyecto de Reglas Uniformes Interamericanas en materia de Documentos y Firmas Electrónicos. Sexta Conferencia Especializada Internacional sobre Derecho Internacional Privado.

Misión Permanente de Estados Unidos de América ante la Organización de Estados Americanos (2004). Selección de temas para la agenda de la séptima conferencia especializada interamericana sobre derecho internacional privado. Séptima Conferencia Especializada Internacional sobre Derecho Internacional Privado.

Moncayo, V. M. (2004). El leviatán derrotado. Norma.

Noguera Laborde, R. (2002). Introducción General al Derecho. Universidad Sergio Arboleda.

Oficina Nacional de Gobierno Electrónico e Informática. (2005) Estrategia nacional de gobierno electrónico e informática. Presidencia delConsejode Ministros.Perú. [Disponible en: http://www.peru.gob.pe/ propuestasongei $/ 09 \% 2$ EstrategiaNacioal deGobiernoElectronicoeInformatica.pdf]. 
Olivera, N. (febrero de 2008). En busca de la lex retialis. Revista de derecho informático Alfa-Redi. [Disponible en: www.alfaredi.org/rdi-articulo.shtml? $\mathrm{x}=10130]$.

Oviedo Albán, J. (2001). Campo de aplicación $y$ criterios de interpretación de la Convención de Viena para la Compraventa Internacional de Mercaderías. Pace Law School Institute of International Commercial Law. [Disponible en: http:// www.cisg.law.pace.edu/cisg/biblio/alban. html\#7].

Oviedo Albán, J. (2004). Regulación del contrato de compraventa internacional. Antecedentes, estructura y fuentes. Ibáñez.

Pájaro Moreno, N. (2006). Autonomía Privada y Constitucionalización del Derecho. Universidad Externado de Colombia.

Radbrusch, G. (1947). Introducción a la filosofia del derecho. Fondo de cultura económica. [Disponible en: http://books.google.es/ books?id=ySRP_YTemq4 C\&pg=PA40\& sig=ACfU3U3HfKM3jXjiwhwb].

Ravassa Moreno, G.J. (2002). Derecho Mercantil Internacional. Principios $y$ normas. Ibáñez. Universidad Santo Tomás.

Reale, M. (1982). Introducción al Derecho. Ediciones Pirámide.

Remolina Angarita, N. (2006). Aspectos legales del comercio electrónico, la contratación y la empresa electrónica. Universidad de los Andes. [Disponible en: http://gecti. uniandes.edu.co/docs/comercio $\% 20$ elect\%20Remolina.pdf].

Reusser Monsálvez, C. P. (2003). ¿Qué es la Sociedad de la Información? Revista de Derecho Informático Alfa Redi.
[Disponible en: http://www.alfa-redi.org/ rdi-articulo.shtml? $\mathrm{x}=1307]$.

Rincón Cárdenas, E. (2004). Últimos retos para el derecho privado: las nuevas tecnologías de la información. Revista de Estudios socio-jurídicos. [Disponible en: http:// redalyc.uaemex.mx/redalyc/src/inicio/ ArtPdfRed.jsp?iCve=73360215].

Rincón Cárdenas, E. (2006a). Manual de derecho de comercio electrónico y de Internet. Universidad del Rosario.

Rincón Cárdenas, E. (2006b). Contratación electrónica. Universidad del Rosario.

Ríos Ruiz, W.R. (2007). Escenario y Marco Legal de la Factura Electrónica en Colombia. In (Revista Derecho, Comunicaciones y Nuevas Tecnologias). Universidad de los Andes. [Disponible en: http://derechoytics.uniandes.edu.co/ contenido/articulos.php?numero $=3 \&$ idar ticulos $=23 \&$ tipos $=$ Ensayos $]$.

Rodríguez Azuero, S. (2006). Referencias a la contratación bancaria electrónica en Colombia. In (cap. Contratos Electrónicos). Universidad del Rosario.

Sánchez Sánchez, E.R. (2001). El comercio electrónico en el Perú. Revista Punto de Equilibrio. Universidad del pacífico.

Sandoval López, R. (2003). Derecho del comercio electrónico. Editorial jurídica de Chile.

Sergio Arboleda, U. (2008). Documento dirigido al Ministerio de Educación Nacional en respuesta al auto expedido por el Viceministerio de Educación Superior el día 18 de junio de 2008 respecto de la Solicitud de Registro Calificado del programa de Especialización en Derecho de los Contratos con Énfasis 
en Contratación Internacional de la Universidad Sergio Arboleda en la ciudad de Bogotá D.C., metodología presencial.

Silveira, M. (2001). Repercusiones internacionales del comercio electrónico: el marco legal del comercio electrónico en America Latina y la necesidad de armonizar la normativa aplicable. Revista de la contratación electrónica. [Disponible en: http://europa.sim.ucm. es/compludocAA? $\mathrm{a}=$ Silveira $\% 2 \mathrm{c}+$ Maria $\mathrm{na}+\mathrm{C} \% 2 \mathrm{e} \&$ donde $=$ castellano\&zfr $=0]$.

Solarte Rodríguez, A. (2008) La buena fe contractual y los deberes secundarios de conducta (In chap. Derecho privado y globalización. Tomo III. Contratos). Ibáñez.

Suescún Melo, J. (1996). Estudios de Derecho Civily Comercial Contemporáneo. Cámara de Comercio de Bogotá - Universidad de Los Andes. Bogotá.

Superintendencia de Industria y Comercio (2003). Concepto 02117239 del 13 de Febrero de 2003. [Disponible en: http:// www.sic.gov.co/Conceptos/Conceptos/ 2003/Febrero/02117239.php].

Torres, J. (1994). Globalización e Interdisciplinariedad. Morata. Disponible en: http://
books.google.com.co/books?hl=es\&idA 3hUd70u0wAC\&dq=interdisciplinaried ad\&printsec $=$ frontcover\&source $=$ web \& ots $=$ XJbhqOAuvU\&sig $=\mathrm{B} 6 \mathrm{mE} 4 \mathrm{xwYm}$ diSoFKZDJLCJ0psMwM\&sa $=$ X\&oi $=b$ ook result\&resnum $=8 \& \mathrm{ct}=$ result $\#$ PPA5 4,M1

Umaña Chaux, A.F. (2006). Contratación electrónica internacional. In (cap. Contratación Electrónica). Universidad del Rosario.

Valencia Zea, A. (1981). Derecho Civil. Parte General y Personas. Novena Edición. Temis.

Vessuri, H. (2008). Tendencias de la Educación Superior en América Latina y el Caribe. In (cap. El Futuro nos alcanza: Mutaciones previsibles de la ciencia y la tecnología). Instituto Internacional de la Unesco para la Educación Superior en América Latina y el Caribe (IESALC).

Zarur Miranda, X. (2008). Tendencias de la Educación Superior en América Latina y el Caribe. In (cap. Integración Regional e Internacionalización de la Educación Superior en América Latina y el Caribe). Instituto Internacional de la Unesco para la Educación Superior en América Latina y el Caribe (IESALC). 
